\title{
A Place-Based Ethic of Care: The Beginnings of the Utah School
}

\author{
KEITH DIAZ MOORE \\ University of Utah
}

This manuscript provides a case study of how Tronto's Ethic of Care and the particularity of place for a College of Architecture and Planning has informed the thought process of curricular transformation discussions. Tronto's ethic of care expresses four ethical elements: attentiveness, responsibility, competence and responsiveness. These four have been negotiated with place-based considerations capture in the phrase "the idea of mountain." This negotiation results in four commitments and the recognition of mindsets and attitudes faculty seek to develop through pedagogical transformation. The four commitments are: resilience, responsibility, respect and response which capture interdependencies between mindsets (systemic, empathetic) and attitudes (humility, urgency) asserted to be essential to 21st century environmental design. Such massive change suggests a thorough reconsideration of the "hidden curriculum" found in the design disciplines, particularly of early design education. Rather than beginning with skills and knowledge as is typically found in architecture curricula, this College has launched a Design Foundations sequence of three courses that provides an initial interaction with the mindsets and attitudes expressed above. Focus becomes on preparing the mind and character necessary to become agents of transformational change regardless of students' eventual disciplinary choice.

\section{INTRODUCTION}

One of the first impressions for visitors to the Salt Lake Valley as they arrive at the airport is that no matter which direction you look, there is a mountain view. It is breathtaking to see a thriving metropolitan region-one now referred to as the "Silicon Slopes"1 -located in such a beautiful setting. The Wasatch Mountains to the North and East provide shelter from "Alberta Clipper" winter winds that chill places like Wyoming and the Dakotas, providing for more mild than expected winter temperatures. Yet this beauty also comes with complicating factors. The climate affords the Salt Lake Valley an average of only 16.5 inches of rain annually, with hardly any participation in the summer months, making water conservation a critical need. The surrounding mountains also create a natural petri dish leading to inversions where pollutants get trapped by air masses, resulting in our 7th worst ranking for air pollution by the American Lung Association. ${ }^{2}$ These criticalities are being exacerbated by the fact that the Salt Lake Metropolitan Area is the tenth fastest growing metro region, with the fourth fastest growing job sector in the United States. ${ }^{3}$ It is also, of course, home to the Latter-Day Saints, and by Brigham Young's proclamation that "this is the right place," possesses the imprimatur of divine selection. Once settled, by the LDS pioneers, Young sent missionaries out around the world, and found great success in Scandinavia, providing explanation as to why about 50 percent of Utah has Scandinavian lineage.

These conditions create two opposing ideas of "mountain" which repeatedly contradict one another: that the valley created by the mountains is a place of dearth, dirt and hardship; or conversely, that it is, what Peter Davidson describes the Idea of north as, "a place of austere felicity where virtuous peoples live behind the north wind and are happy." ${ }^{\prime \prime}$ It is within this dialectic that the College of Architecture and Planning began its conversation of developing a place-based vision for design education.

\section{THE IDEA OF MOUNTAIN \\ "Man has not learned to think like a mountain." - Aldo Leopold ${ }^{5}$}

In his writing on nature, Leopold notes that it is humanity's preference for dominion that prevents its ability to achieve balance with nature. Such necessary interdependence is only highlighted in a challenging ecology such as the Salt Lake Valley. When we first experience a mountain setting we are struck both by its conveyed strength and its permanence. Yet those that have the privilege of experiencing mountains daily know that strength belies a great ecological fragility. This fragility may be in terms of water scarcity/surplus, of infestation (e.g.Bark beetles), or of delicately balanced microclimates. All of these forces point to the fact that nor is the mountain permanent, but rather ever-changing. The same hike changes throughout the year, reflecting a never-ending ecological choreography in mountain settings.

In literature, mountains speak of aspirations. Wisdom is often viewed as located at a mountaintop, typically in the form of the "wise man." Dr. Martin Luther King, Jr. asked us all to aspire by harkening that he "had been to the mountaintop." Therefore the ubiquitous mountain view found in the Salt Lake Valley serves as a constant reminder that we are to aspire to think like a mountain. Taken together, we are to aspire for resilience; to operate within systems whose homeostasis is so well-tuned, that they can quickly recover from challenges.

As with living in the North, mountain living may equally be referred to as demanding "austere felicity," austere meaning 
only that which is necessary and felicity meaning appropriateness or eloquence. These two critical concepts associated with the harsh climate of North are equally suited to the harsh realities of mountain living. In Swedish, "austere felicity" is embodied in the cultural concept of "Lagom," whose meaning is conveyed through a proverb whose point is that enough is as good as a feast. A popular etymological translation to the Viking era is "team around" meaning to take a proper amount so that there is enough food or drink for everyone at the table. Thus in all that we do, we should take only that which we need and always take care of those that follow. In this way, we have a responsibility to future generations for the decisions we make today in terms of interacting with our natural resources.

Another characteristic of the mountain environment is that every location is quite unique, due to dramatic effects of the mountain in terms of light, precipitation, wind and the like. The mountain landscape demands that interventions are site specific, or in the words of Peter Zumthor, "every building is built for a specific use in a specific place for a specific society." ${ }^{\prime 6}$ Sites in mountain landscapes can host numerous microclimates host a biodiversity that is careful balance with one another. The concept of "particularity of place" cannot find greater resonance than in the eco-diverse mountain landscape and is a sensibility that must have respect.

Yet it is also true that the Salt Lake Valley is a contested landscape. This is highlighted by several pressing socio-environmental issues confronting the region. First and foremost is our already mentioned significant environmental issues, such as air quality. Climate models together with the regular multi-decade variation of the North Atlantic Oscillation suggest that the coming two decades will see three times as much inversion pollution levels. ${ }^{7}$ The Salt Lake Valley is also a region at high risk for water scarcity. Climate change models suggest creeks and streams drying 2 to 4 weeks earlier in the year by the mid-century. This concern is then multiplied by the population growth of $93 \%$ ( 3 million to 5.8 million) projected for the state over the next 50 years. ${ }^{8}$ Second, our populous is in rapid demographic change particularly in terms of diversity with growth in Hispanic, Asian and Pacific Islander populations. These populations are young adults on average, meaning their in-migration will be multiplied over the coming decades as they have children and grandchildren. Third, is our chronic homelessness issue paired with a noxious shortage of affordable housing. Typically, in a healthy housing market, the development of housing units outpace the growth in households by 5 to 10 percent. In Salt Lake City, new housing units trail household growth by 30 percent. $^{9}$ Together with low wages and growing opiate addiction, the homelessness problem has grown to crisis proportions. ${ }^{10}$ With this in mind, our landscape also challenges designers to respond to the local manifestations of global challenges.

\section{AN ETHIC OF CARE}

"With all architects, caring should be the ethical imperative."11

-E. Fay Jones

Emerging within feminist theory, an ethic of care emphasizes the concept of interdependence between a fragile world and the imperative to care for it. ${ }^{12,13}$ Rather than referencing external ideas about morality, the ethic of care emphasizes sensibilities and skills, or in other words, a habitualized practice that may be refined over time. Tronto has identified four ethical elements of care: attentiveness, responsibility, competence and responsiveness. ${ }^{13}$ Attentiveness is akin to empathetic: a recognition of the needs of others in order to then respond to them. Tronto identifies two dimensions to attentiveness: awareness and willingness. It is possible for someone to be ignorant of issues and/or circumstances, but the larger question is if there is a willingness to learn and engage? Responsibility is not to be confused with obligation, or in the case of architecture, professional obligation. Rather, responsibility is an internal sensibility captured in the phrase, "if not me than who?" But it is also here where the word "careful" comes into play: we are to act with humility or in ways that acknowledge what we do not know. Competence has to do with the abilities necessary to respond effectively. These may be skills or knowledge-based, but also sensitivitybased. Responsiveness actually deals with the receptivity of the care receiver to the care provided. Time is a crucial factor: is the care-giving and the care-receiving not only aligned in kind but in time. This again highlights the interdependence of the parts of the caring system involved.

As Bates, Imrie and Kullman observe, "the notion of care occupies a relatively minimal position within design."14 Yet there are strong parallels between the concepts emergent from our exploration of the idea of mountain (resilience, responsibility, respect and response) and Tronto's four ethical elements of care (attentiveness, responsibility, competence and responsiveness). In discussing the four ethical elements above two dimensions of orientation toward the world: mindsets and attitudes. Two mindsets discussed are the empathetic and the systemic while two attitudes were humility and urgency. Figure 1 maps the empathetic and systemic mindsets on the vertical access and the attitudes of humility and urgency on the horizontal access. This creates a quadrant system into which is mapped the key words stemming from both Tronto's ethic of care and the idea of mountain. Quadrant I captures the terms response and responsiveness which both capture the immediacy of care action and the need to be empathetic to the other dimensions of the system. Quadrant II includes both respect and attentiveness which highlight the humility of not knowing all and the empathetic impulses it takes to gain critical insight. Quadrant III contains the word responsibility from both approaches and highlights both the humility and systemic awareness necessary to demonstrate responsibility. 


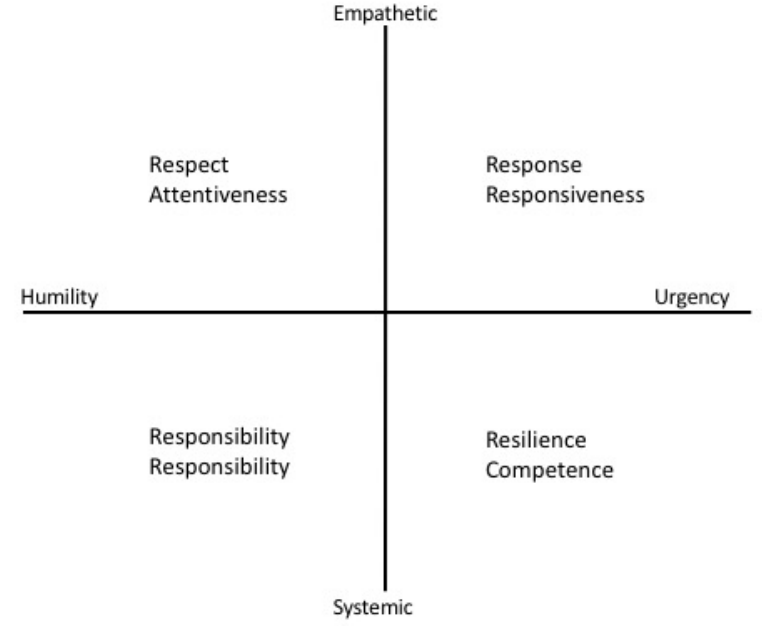

Figure 1: Conceptual Framework mapping 4 commitments and 4 ethical elements in relation to mindsets and attitudes.

Finally, Quadrant IV highlights the urgency and systemic nature of the knowledge, skills and attitudes necessary to exercise competence and to achieve resilience.

\section{A PLACE-BASED ETHIC OF CARE}

Figure 1 presents a shorthand of the guiding framework that has shaped both the vision of the Utah School and is currently guiding our curriculum transformation efforts. The Vision of the College of Architecture and Planning at the University of Utah (CA+P) asserts four commitments:

1. Responsibility: A responsibility to past, present and future generations for the sustainability of our creative expressions that reallocate natural resources

2. Resilience: A systemic understanding that polycultures and diversity nurture greater ecological and community resilience.

3. Respect: A respect for the health and culture of all people and places

4. Response: The demand to respond to the local manifestations of the grand challenges of our time through innovative and collaborative modes of practice that demonstrate our commitment to excellence and quality.

With these commitments in mind, we are beginning to incrementally change our curricula across the college, in architecture, design and planning. Our initial discussions centered on the early curriculum we desired across the disciplines responsible for our designed world. While all too often early curricula focus on skills and knowledge, we have crafted a first-year sequence of three courses whose emphasis is on the honing of mindsets. Rather than beginning with How and What, our shorthand for this reorientation is to "Begin with Why." This is why this was the theme of our recently-hosted National Conference on the Beginning Design Student in 2017.
Design Foundations. Up until the Fall of 2017, the undergraduate offerings within $\mathrm{CA}+\mathrm{P}$ began in a students third, or junior, year while their first two years were spent as a general university student. With the creation of a new entry point for students, the opportunity to reconsider entry, or foundational, level education for designs students became not only possible but of a necessity. As such, we were able to recognize that introductions to architectural history and graphics are often conducted absent of why their content is important. We also knew that such courses privileged certain backgrounds and experiences and thus were overly determinative of the students who were likely to matriculate into upper division in our majors. This was of particular concern for our faculty as we highly value inclusivity within our community and believe that only enhances the depth and resilience of our college, the university, the profession and of society. In our particular case, for instance, our first pre-major architectural graphics class was largely the looking glass through which students needed to pass in order to enter the architecture major. Yet we know that graphic skills are often long to mature and, perhaps more importantly, can be questioned as the definitive domain for competence in what is now a diverse architectural profession.

Often, both introductory graphics and history classes are taught within an historically art education rooted approach. Yet what we have found is that students who leave the program do not head to the Fine Arts, but often to Social Work, Strategic Communications and the Social Sciences. To us, this signaled that our working curricular assumption that students interested in architecture are emerging from an artistic root, was flawed; that most students were coming from a social and/or environmental justice root and seeking a profession from which to enact change. Our pre-major courses were driving them away by not speaking to their agentic predispositions. Similarly, those courses were not instilling the 21st century mindset we sought to build within our students, which is actually more in line with empowering agents of transformative change.

We looked at Howard Gardner's Five Minds of the Future as well as Daniel Pink's A Whole New Mind to help inform our thoughts. ${ }^{15,16}$ What emerged were three mindsets that capture all five outlined by Gardner: ecological thinking (the ethical mind), design thinking (creating and synthesizing minds), contextual thinking (disciplined and respectful minds). While each mindset may be addressed in all classes, we developed three foundation courses each focused primarily on one of these three mindsets. Design Ecologies is designed to introduce students to the complex world of systems thinking and our moral and ethical obligation to being balanced stewards of the environment and of community. Design Workshop emphasizes human-centered design and the rigors of creative design thinking processes. Design Contexts is in some ways the most ambitious course, raising awareness of the core 


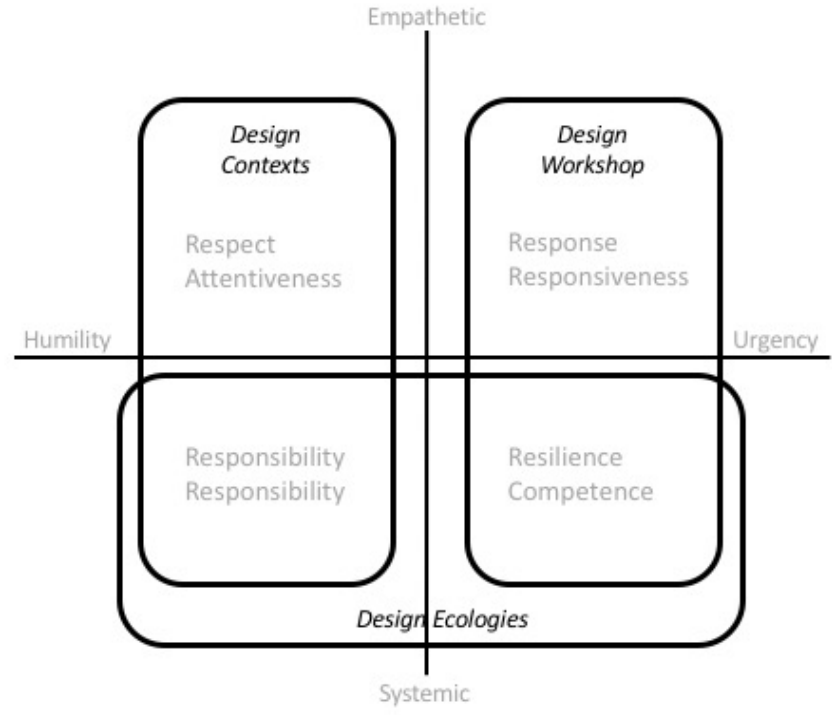

Figure 2: Mapping three new Design Foundations courses onto Figure 1 Conceptual Framework.

aspects of each design discipline and how these relate at various environmental scales (proximate, building, neighborhood, settlement), while always emphasizing the core characteristic of respect as intrinsic to our professions.

In terms of the four commitments, Figure 2 captures how we see these "4R's" emphasized. Design Ecologies focus on the systemic side of Figure 1, with learning objectives focused on the ethical responsibility of the professions espoused in the College Vision as well as how a systemic approach is essential to creative responses that can further community and ecological resilience. The key term for the class is "relationships;" exploring how people relate in different ways to various specific phenomena challenging local resilience (e.g. spatially, economically, emotionally). Example topics chosen by these freshmen students include how sex trafficking is spatialized; and tracking personal contribution to the waste system, and in turn, from where those resources initially matriculated. Discussion of these projects results in the need for the class to provide a brave space for ethical dialogue.

Design Contexts emphasizes the humility found in Quadrants II and III, by connecting the responsibility we hold as environmental stewards to the importance of respect for diverse perspectives - whether those differences are disciplinary, value-based or experiential in nature. Scale jumping is at the heart of this class, with design vignettes in the labs moving from a water bottle to a building entrance to a small plaza all focused on issues of materials, flows (of both water and people) and cultural understandings. An underlying framework is that of the International Living Future Institute and their Living Building Challenge, Living Product Challenge and Living Community Challenge. Each of these utilize the same set of seven performance areas: Place, Water, Energy, Health + Happiness, Materials, Equity and Beauty. ${ }^{17}$
Finally, Design Workshop emphasizes the action orientation spurred by the "fierce urgency of now" found in Quadrants I and IV. Our communities and ecologies demand healing to enhance resilience and design workshop attempts to provide well-crafted and controlled learning opportunities to respond to the challenges of our time in a manner accessible to the beginning design student. This class makes the strong proposition that at the heart of craft is the concept of caring for others - that that will use and produce the artifact as well as for the environments that provide the materials and/or accommodate that intervention. Craft is an essential integrity for those seeking to address the issues and ethics discovered in the other two classes.

We are now one semester into this new curriculum and together, students seem to indeed be emerging with a more holistic understanding of design and the various professions. One student wrote in a scholarship application after $3 / 4$ of the semester into her University career in Design Foundations:

\section{As a freshman Design Foundations student, I have learned that while design most definitely involves creation, it also encompasses ethical responsibility, active citizenship, humility, and persistence to solve problems through an iterative process. It necessitates a willingness to listen to the needs of others, to collaborate with experts and the public, and to be a part of something infinitely greater than ourselves: the fate of our planet.}

Continuing Curricula Transformation. Given this new shared foundation, each program is now engaged in conversations about how both our vision and our new early education experiences demand change in our traditional curricula. Architecture is embracing the diversity of roles and abilities demanded in a continuously evolving profession and consider radical alteration in terms of curricular structure and delivery of material. The emergent model speaks to divergent learning styles: rather than repetitive semesters of a core studio with parallel support courses, the proposed curriculum speaks to variation in structure, timing and teaching styles. Our planning program has already embraced a radical reconceptualization of their undergraduate experience as one in the domain of urban ecology. Here they are attempting to focus on enhancing student skills at being diagnosticians of our urban living condition. Our multi-disciplinary design program is whole heartedly embracing social entrepreneurship and the need for students to take leadership roles in creating interventions, whether they be products, interfaces or enterprises, that enhance social and environmental justice. As such, their curricular direction is aiming towards greater agility and student choice rather than lockstep curricula we so often see in our professional education. In short, both due to pragmatic (students have now started the first year in our design foundations program) and ethical (our professional education demands radical change now) necessity, our programs are seizing the opportunity to 
take risks and radically reconsider design education for the 21st century.

\section{LESSONS LEARNED}

In terms of curriculum transformation, we have found it exceptionally useful to bring in creative voices to work with us in a series of retreats. These have included Renee Cheng and Tom Fisher (University of Minnesota), Brook Muller (University of Oregon), Liz Ogbu (Studio O) and David Broz (Gensler) from the architecture realm. These progressive thought leaders have challenged us to move aggressively in terms of: shifting assumed structures of architectural education; consider health and ecological dimensions as central to the creative challenge; to carefully consider how design may further complicity challenging resilience; and to realize that the academic setting is a place and we should continuously engage in collective place-making. We find these presentations, which we call "provocations," to help us recommit to the difficulty but ennobling journey that we are on.

Regarding Design Foundations, we see great potential for this program after our inaugural semester, but know we can do better. Our classes remain isolated from one another and we aim to braid them together in appropriate ways to make the learning experience even more integrated. Our Design Workshop is moving aggressively to emphasize the importance of both visual curation of work and timely reflection on the process of creation. We also know that this new foundation, with its focus on the ethic of care, will provide immediate challenges to our curriculum transformation discussions. We can already sense that these students will be energized and focused on addressing the global challenges of our time and that our accredited curricula will need to raise their game to harness this ethical energy through the problems and assignments we craft. The proposition is thrilling: simultaneously scary but very energizing.

\section{CONCLUSION}

The College of Architecture and Planning at the University of Utah is on a journey; a journey of creating design education that is rooted in the ethic of care and inspired by our genius loci. We believe an ethic of care has multiple, interconnected implications for education. Rather than focused on skills and knowledge, because an ethic of care is centered on the interdependencies in the world, our curriculum needs to focus on mindsets and attitudes. This is not to say disciplinary skills and knowledge disappear, but neither are they the raison d'etre of our curricula often implied by accreditation requirements. Rather, we are able to situate those skills and that knowledge within the penultimate context of an ethic of care which asks the question, "how to respond?" Thus we are able to speak to the belief that those skills and knowledge become essential because we seek to respond effectively to create a more resilient world. Hence the importance of beginning with, why.
What gave birth to this exciting journey was a special collection of faculty, students and professional community poised to question prevailing paradigms. This willingness is due in no small part to the significant local manifestations of global challenges we experience on a daily basis. Our ecological fragility, air pollution, homelessness and the like all have environmental design dimensions that suggest our professions are not enhancing, let alone maintaining, the health, safety and welfare of our citizens and our planet. Yet simultaneously, our environs provide us ubiquitous reminders that we are called to aspire; to "think like a mountain." We need to take risk, be bold, and do so rooted in an ethic of care. Time will tell where this journey take us, but we are on a pioneering, empowering path and the journey is as critical as the destination.

\section{ACKNOWLEDGEMENTS}

This paper would not have been possible without the energy and creativity of all of our faculty, students and professional community. Particular thanks, however, must go to the lead faculty tasked with making our Design Foundations come to life: Stephen Goldsmith, Mimi Locher and Elpitha Tsoutsounakis. I am endebted to them for making their good work available.

\section{ENDNOTES}

1 Gill, R. "A superhero on Utah's silicon slopes." The Construction and Practice of Entrepreneurial Identities at the Nexus of Religion, Gender, and Place, The University of Utah, Salt Lake City, UT (2012).

2 American Lung Association webpage. "How healthy is the air you breathe?" Accessed 09 September, 2017.

3 Kotkin, J. Forbes.com webpage "No. 4: Salt Lake City.” Published 27 May, 2012.

4 Davidson, Peter. The Idea of North. Reaktion Books, 2005, p.21.

5 Leopold, Aldo. A Sand County almanac: With other essays on conservation from Round River. Random House Digital, Inc., 1970, p 132.

6 Zumthor, Peter, et al. Thinking Architecture. Vol. 113. Boston: Birkhäuser, 2006.

7 Standard-Examiner website. "Environment." Accessed 09 September, 2017.

8 Kem C. Gardner Policy Institute website. "Population Projections." Accessed 10 September, 2017.

9 Kem C. Gardner Policy Institute website. "Does Utah have a housing shortage?" Accessed 10 September, 2017

10 DeseretNews.com website. "Critical mass: How did Salt Lake get to this state of homelessness?" Accessed 10 October, 2016.

11 Jones, E. Fay. Outside the Pale: The Architecture of Fay Jones. University of Arkansas Press, 1999.

12 Noddings, Nel. Happiness and education. Cambridge University Press, 2003

13 Tronto, Joan C. Moral boundaries: A political argument for an ethic of care. Psychology Press, 1993.

14 Bates, Charlotte, Rob Imrie, and Kim Kullman, eds. Care and Design: Bodies, Buildings, Cities. John Wiley \& Sons, 2016, p.10.

15 Gardner, Howard. "The five minds for the future." Schools 5.1/2 (2008): 17-24

16 Pink, Daniel H. A whole new mind: Why right-brainers will rule the future. Penguin, 2006.

17 www.living-futures.org 